\title{
The Transformation of the MPAcc Talent Cultivation Model in Colleges Based on the Financial Shared Environment
}

\author{
Jun Dai*, Mengting Yu \\ School of Management \\ Wuhan University of Science and Technology \\ Wuhan 430081, China \\ daijun78@wust.edu.cn
}

\begin{abstract}
The MPAcc education reform needs to be based on the developing trend of the accounting industry. Exerting the advantages of standardization, process and intelligence, nowadays the financial shared service is leading the revolution of the accounting industry by the modem information technology. This paper analyses the new changes of the responsibility and requirements for the accounting personnel, proposes that the MPAcc education should further strengthen the training in the fields of strategic finance, shared finance and specialized management, and provides a guidance on the training program adjustments in the end. The purpose of this study is to improve the quality of MPAcc talent training to better satisfy the market demand under the tendency of financial shared environment.
\end{abstract}

Keywords: MPAcc: financial shared center; talent cultivation.

\section{INTRODUCTION}

In China, the concept of 'Sharing Economy' was first officially presented in the Fifth Plenary Session of 18 Central Committee in 2015. Under the push of the Sharing Economy development in the whole society, the Financial Shared Services Centre (FSSC), which was born in 1980s in the United States, is experiencing a paragraph of unprecedented erupts type increases level in China. According to the reports from Deloitte Touche Tohmatsu (DDT), Ernst \& Young, and Zhongxing Telecommunication Equipment Corporation (ZTE), FSSC has entered a rapid development phase in China from the concept introduction period. More than half of large Chinese domestic enterprises have started to use financial shared services. A large number of common accountants who once engaged in the traditional accounting have been replaced by FSSC, which have obvious advantages of standardization, streamlining and intelligence. Consequently, the enterprise financial reforms led by FSSC will surely bring forth a great change in the demand structure of accounting talents in the next decade. More and more financial personnel skilled in the strategic decision, financial share, and business operations will be chased by the enterprises with FSSC. Since Master of Professional Accounting (MPAcc) is designed to train high-level applied accounting talents, all the Chinese MPAcc training organizations need to pay more attention to the reform of accounting industry led by financial shared service and explore the novel talent nurturing mode well adapted to FSSC.

With the vigorous development of MPAcc education in our country, the relevant research on MPAcc talent training reforms is constantly emerging. On the whole, the research can be divided into two groups that carry out research in the view of school running units of MPAcc or in the view of educational administrative departments. The former is mostly guided by the 'Reference Training Program for Postgraduate Students Majoring in Accounting' issued by the National MPAcc Education Steering Committee in 2014, and the latter mostly engaged in exploring the reform direction of the MPAcc talent training mode by combing the advantages of school-running units with the demand of regional economic development on the accountant talents. Hu Guoqiang and Wu Lei(2015), Tang Hongxiang and Li Chunyou(2016) put forward a talent training program named ' Based on Guangxi, radiate ASEAN(the Association of Southeast Asian Nations) ' as the MPAcc education features of Guangxi University of Finance and Economics. This training program takes 'serving the national demands on special talents' as the MPAcc characteristics by adding some elective courses, such as 'China-ASEAN Accounting Comparison' and 'ASEAN Commercial Law' in the curricula system. Since the number of MPAcc training organizations in China has rapidly increased to 177 until 2015, Luo Liping and Jiang Hongyun(2015)considered that the local universities and colleges of science and technology should design their MPAcc development directions based on better serving the local economy and steadfastly sticking to fully exerting their industry characteristics and advantages.

Let's return to the fundamental question of 'how to manage successfully the MPAcc education in China'. Reviewing current research, many studies closely follow the hotspots of the national and local macro economic reforms, such as 'Belt and Road', 'Made in China 2015', and 'Free Trade Zone and Yangtze River Economic Belt', which clearly point out the MPAcc education development direction from the accounting talents demand side. There is no question that the above hotspots are all very good research perspectives. However, in our views doing well in MPAcc education should more focus on the talents demand of accounting industry itself, especially the new demand of financial shared service. To our knowledge, so far domestic research in this area is still in a blank stage. In view of this, this paper intends to carry out a more comprehensive discussion on how to realize the transformation of the MPAcc talent training mode in colleges and universities under the trend of the financial 
shared service.

\section{RESPONSIBILITY AND CAPABILITY REQUIREMENTS OF ACCOUNTING POSITIONS IN THE FINANCIAL SHARED ENVIRONMENT}

On the basis of a large number of financial shared cases analyses, Bergeron proposed that FSSC is a new financial management model, which relies on information technology and process reengineering that concentrate the accounting business, which is easy to standardize, disperse, and repeat, into a new independent business unit. FSSC has some advantages, such as reducing cost, improving efficiency, strengthening control, so that it can enhance the enterprise value. The investigation shows that ZTE has saved 50 to 70 percent of its financial operating costs, and increased the efficiency of financial processing from 2.8 days in the past to 0.22 days in the present since it adopted the financial shared service in 2012.

At the same time, financial shared service has also brought about a huge demand changes in the accounting talent demand. Generally, the financial positions in a traditional enterprise can be divided into financial accounting, financial management and management accounting, in which the proportion of financial accounting personnel is often the largest. However, with the emergence of FSSC the enterprise accounting departments display an increasing trend of the coexistence of concentration and decentralization. Financial accounting work, such as accounting, transaction processing and fund settlement, which are generally dispersed in various subsidiaries of large enterprises, are all centrally handled by FSSC in a standardized, streamlined and large scaled process. In addition, the corporate strategic finance is promoted to the collective headquarters level, and the financial managements on the capital structure, tax planning are carried out by the different expert teams. However, the management accounting gradually present a decentralized trend, and many positions sink to the front end of each business. Thus, it will be more convenient to provide financial decision support for the whole value chain creation process including the product development, product procurement, production and marketing. Taking Haier Group as an example, $10 \%$ faculties in the finance department plays the role of strategic financial managers, $20 \%$ faculties work on accounting in the collective financial shared service center, and $70 \%$ of the financial personnel are arranged at the various business units of Haier Group assuming the responsibilities of management accounting. Through the investigation of the FSSC in Haier, Vanke, ZTE, the divisions of accounting positions in the financial shared environments can be summarized as shown in Figure 1 below.

Strategic financial management refers to the overall, long-term, systematic and decisive planning around the objectives, direction and realization path of accounting and finance activities, which aims to seek the enterprise long-term development. A successful strategic financial management must comprehensively consider the law of enterprise capital movement and strategic development planning as well as the analysis of the possible impact of the future enterprise internal and external environment changes on the financial activities. Strategic financial positions are mainly concentrated at the enterprise group level. Their main responsibility is to formulate the specific value management strategies, such as the investment strategy, the fund-raising strategy, the operating strategy, the dividend strategy etc., and to construct and maintain a financial system at the enterprise group level.

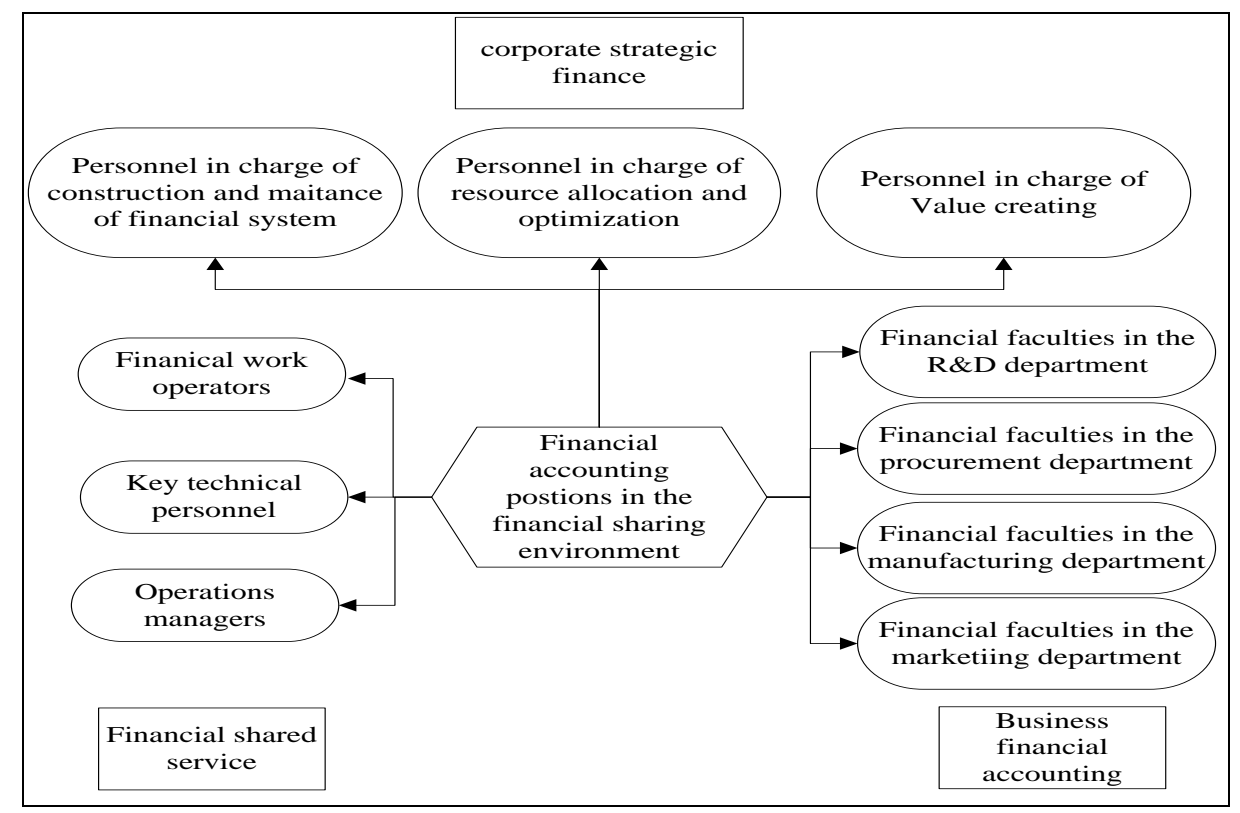

Figure 1 The divisions of financial account positions in the financial shared environment

Here the financial system consists of financial information generation and summary system, financial regulations and policy system, budget and performance evaluation system and risk management system. The 
enterprise groups with strategic financial departments will strive for achieving the strategic financial target by establishing a compound nice pool of high-quality talents with financial personnel as the core and other various talents in finance, strategy, law, statistics, and engineering fields as key members.

The positions in FSSC mainly include financial work operators, key technicians and operational managers. In general, the financial operators can complete standard accounting and fund settlement operations after basic trains in shared financial operations. Therefore, faculties with college degree or below prove adequate to the job. Key technical personnel are the designers of the business standardization and process of FSSC, and are able to complete much key technical work such as data management, process optimization, accounting management, accounting support and technological innovation. The operational managers are mainly responsible for the day-to-day operation and management of FSSC. They not only need the basic knowledge of financial accounting, be familiar with the whole process of FSSC but also have strong team management, communication and coordination abilities.

Business financial accounting is extended into the enterprise $R \& D$, supply, production and sale chains departments, and works on establishing a comprehensive integration information process driven by the business events. It consists of several sub-processes including business process, financial accounting process and management process. Meanwhile, business financial accounting also help each business unit better achieve its objects by promoting scientific business decisions in the way of offering cost management, budget management, financing support and financial performance management.

As shown in the above Figure 1, it is easy to see that the demand for management accounting and strategic financial personnel in the accounting profession will increase greatly in the future. With more and more financial personnel relieved from heavy basic accounting work due to FSSC, the internal accounting division of the enterprise will be further refined in the future. Except for the strategic financial position that needs comprehensive talents with all-round development because of the high requirements, the positions in FSSC and management accounting departments will develop in the more specialized direction, and therefore will need more expert accounting personnel.

\section{TRANSFORMATION OF THE MPACC TRAINING MODE UNDER THE TREND OF FINANCIAL SHARED SERVICE}

MPAcc training institutions are the important educational bases for cultivating high-level and applied accounting talents. In light of the new trend of the rapid financial shared service development, it is necessary to further optimize the MPAcc talent training mode, and strive to cultivate highly qualified, application-oriented expert talents with the ability to find, analyze and solve problems in specific financial fields. For a long time, the MPAcc training colleges and universities have overemphasized the importance of training financial accounting ability. However, in the long-term trend of deepening accounting division, the enterprise financial accounting work will be gradually carried out by FSSC, and the compound financial talents with strong financial management ability and the background of basic accounting knowledge will be more popular in the near future. Therefore, we put forward to reform MPAcc talent training in colleges and universities as shown below.

\section{A. Training Target Adjustment}

In 2014, the National MPAcc Teaching and Pointing Committee issued a notice on the 'Reference Training Program for Postgraduate Students Majoring in Accounting' which gave the principle requirements for the MPAcc training objectives and program, the core of which is to cultivate high quality, applied, international accounting professionals with business competence, mastering modern accounting, finance, audit and related areas of professional knowledge, and ability to solve practical problems. In respond to the analysis of the enterprise accounting talent demand change under the trend of financial shared service as stated above, the training goal of MPAcc can be further clarified on the basis of principle guidance, that is, to train the comprehensive financial talents needed in strategic finance, special talents in financial shared operation and management accounting professionals with strong professional knowledge in a certain field.

\section{B. Training Direction and Curriculum System Adjustment}

At present, the MPAcc National Committee of Teaching and Pointing has provided 4 required courses and 37 optional courses as reference for the formulation of MPAcc curricula system, and requires each training unit to design their featured curriculum modular based on their training direction from the above 37 elective courses. With regard to the new training objective under the trend of financial shared service, each MPAcc training university should make further adjustments in the training direction and the corresponding curriculum, and focus on strengthening the construction of courses on management accounting, shared finance, strategic finance and those belong to interdisciplinary related majors. All of the above measures are to meet the new position requirements of the competence, knowledge and skills for the accounting talents in the financial shared environment. The details are as shown in Figure 2: 


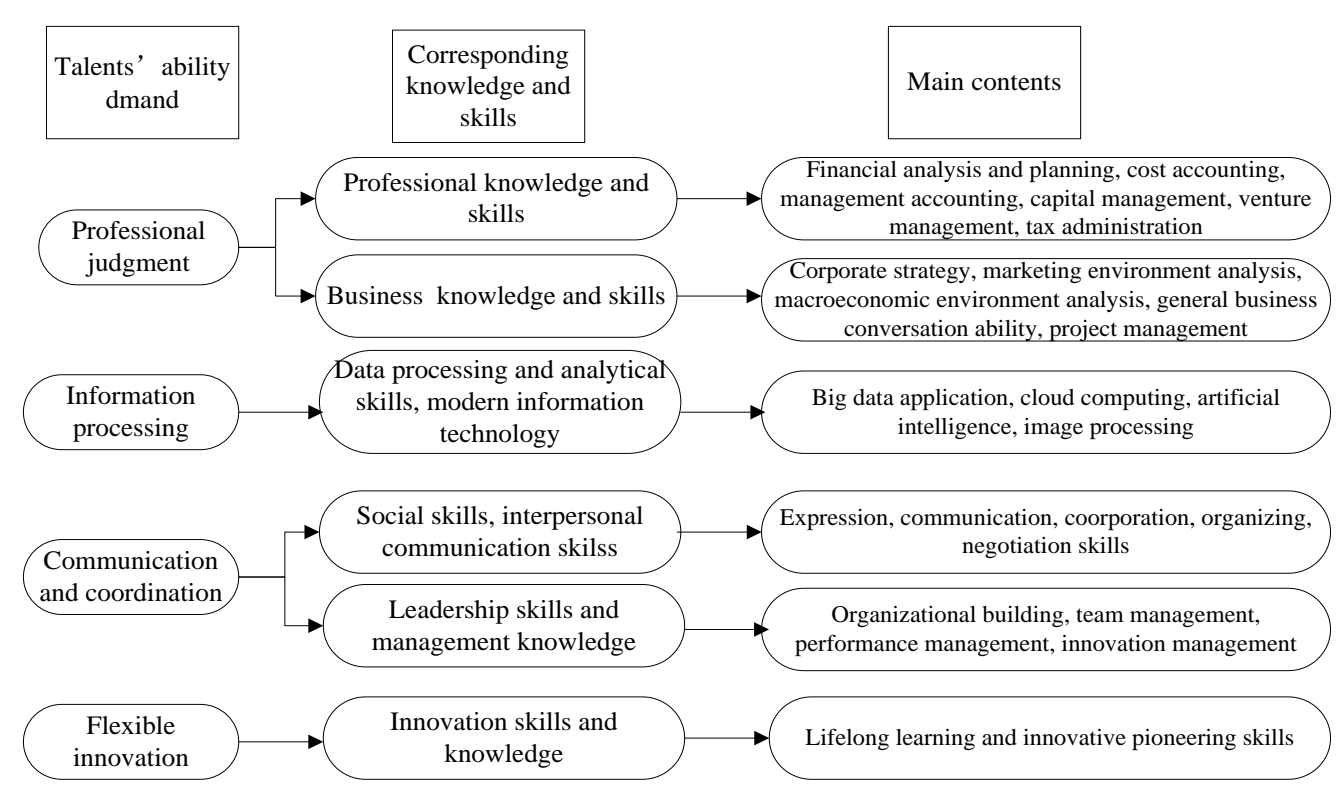

Figure 2 Ability and skills demand for accounting talents in the financial shared environment

\section{Teaching Reform Measures}

In order to train the applied senior accountants in the fields of strategic finance, financial shared service and professional management accounting, MPAcc colleges and universities must break the traditional class teaching methods that emphasize imparting knowledge to students. Instead, case teaching discussion, task simulation and other novel teaching methods should be more adopted from the point of the actual business activities. The teaching content of MPAcc should be close to the actual financial problems of enterprises as far as possible. Furthermore, in the practical teaching the MPAcc colleges and universities should make great efforts to strengthen the cooperation between university and enterprise, closely connect the FSSC in large enterprises, and try to improve the student's ability on solving practical problems plus comprehensive professional skills and excellent professional qualities. In addition, the selection of MPAcc dual mentors should comes from senior financial personnel such as the senior FSSC operation manager, chief accountant, chief economist, head of finance department of the group enterprises who are experts in the fields of strategic finance, shared services, and financial integration. Besides, in view of the lack of channels for colleges and universities to contact the high-quality enterprises in the region, it is suggested that these MPAcc training units can take an active part in some relevant trade associations, such as Hubei Provincial Association for Financial shared services, to organize MPAcc students to visit the FSSC in major enterprise groups, and gradually establish a mechanism for colleges and universities to cooperate with industry excellent enterprises to train MPAcc students.

\section{CONCLUSION}

With the rapid development of financial shared services, the financial accounting departments of enterprise groups have increasingly been divided into four parts: Strategic financial management, financial shared services, business financial accounting and a team of experts with a 'four in one' structure. These four financial divisions complement and coordinate with each other and jointly achieve the financial objectives of the enterprise. Under the background of growing specialisation in the accounting industry, the MPAcc training colleges and universities need to focus on the four fields: strategy, sharing, business and specialists, to improve the curriculum system, perfect practical operation, and strive to cultivate senior accounting management personnel who can better meet the needs of the accounting industry

\section{ACKNOWLEDGMENT}

Supported by the postgraduate education and teaching reform program of Wuhan University of Science and Technology: the training model of local institutes' MPAcc education based on the perspective of regional economic demand (Yjg201606)

\section{REFERENCE}

[1] Hu G.Q., Mo L., the Practice of the MPAcc Talents Training Project for Serving the National Special Needs_the Case of Guangxi University of Finance and Economics, the friends of the accountant, 2015, 9(18): 122-125

[2] Tang H.X., Li C.Y., Analysis of SWOT and Talent Training Mode in the Accounting Professional Master of 'Serving the National Special needs Talent Training Project' _ the Case of Guangxi University of Finance and Economics, Higher Education Forum, 2016, 5(5): 98-101

[3] Luo L.P., Jiang H.Y., the Explore for Features of the Local Polytechnic Institutes' MPAcc Training Education, Survey of Education, 2016, 7(4): 38-40

[4] Bergeron, Essentials of Shared Services, Beijing, People's university publication house, 2011: 21-24

[5] Tang Y., the Transformation of Traditional Financial Accountant in the Financial Shared Environment, Finance and Accounting Monthly, 2015, 19:18-21 